\title{
Predictors of under Five Years Old Diarrhoeal Disease in Mataniko Informal Settlements in Solomon Islands
}

\author{
Ambrose Gali ${ }^{1}$, Masoud Mohammadnezhad ${ }^{2}$, Sabiha Khan ${ }^{2} \&$ John Lowry $^{3}$ \\ ${ }^{1}$ Health Promotion Department, Ministry of Health and Medical Services, Honiara, Solomon Islands \\ ${ }^{2}$ School of Public Health and Primary Care, Fiji National University, Suva, Fiji Islands \\ ${ }^{3}$ School of People, Environment and Planning, Massey University, New Zealand \\ Corresponddence: Masoud Mohammadnezhad, Associate Professor of Public Health (Health Promotion), School \\ of Public Health and Primary Care, Fiji National University, Suva, Fiji Islands. Tel: 679-972-6127.
}

Received: October 9, 2020 Accepted: December 23, 2020 Online Published: January 3, 2021

doi:10.5539/gjhs.v13n2p69 URL: https://doi.org/10.5539/gjhs.v13n2p69

\begin{abstract}
Background: Diarrhoea remains a serious health problem among children under five years (U5y) in the world. Though diarrhoea is a preventable disease, U5y are often at high risk to diarrhoea infection.

Objective: To determine the predictors of diarrhoeal disease among children U5y, in Mataniko informal settlements, in Honiara, Solomon Islands.

Methods: A prospective cross sectional study was conducted at three out of the six randomly selected Mataniko informal settlements situated along the Mataniko River corridor, in Honiara, Solomon Islands. Caregivers with children U5y were included in this study. A total of 205 caregivers being interviewed using a pre-tested survey questionnaire. Data were analyzed using descriptive statistics, followed by binary logistic regression to explore the relationship between the investigated variables. A p-value less than 0.05 was considered to be statistically significant.
\end{abstract}

Results: The results of this study showed that $45.9 \%$ of all caregivers had reported that their U5y children had suffered with at least one episode of diarrhoea within the last 2 weeks prior to the study. Age of children, number of U5y children per caregiver, and fortnightly income level below \$1500 (SBD) were significantly associated with under-five diarrhoea $(\mathrm{p}<0.05)$.

Conclusion: This study showed different factors which were associated with U5y diarrhoea in Solomon Islands. To address these exposures, relevant programmes and preventive strategies should be considered.

Keywords: Prevalence, Predictors, Under-five years old children, Diarrhoeal, Solomon Islands

\section{Introduction}

Though diarrhoea is a preventable disease, it remains the second most serious health problem among under five years (U5y) children in the world (World Health Organization, 2015). Children U5y are often at high risk to diarrhoea infection (Alambo, 2015; Mohammed \& Tamiru, 2014; Solomon Islands National Statistics Office \& Inc, 2009; World Health Organization, 2015). Children in every setting are an important component of the country's population, and therefore their health reflects the status of the national health care system (Chongsuvivatwong et al., 2011; Stella, Huang, \& Singh, 2004). In 2009, it was reported that around 6 million children U5y suffered with diarrhoea each year (World Health Organization, 2009a), and more than half of the annual reported diarrhoea cases were from developing regions in Africa and South Asia, where childhood diarrhoea is more likely to result in death (Unicef, 2004; Wardlaw, Salama, Brocklehurst, Chopra, \& Mason, 2010). Furthermore, it is found that most children who died from diarrhoea died mainly due to severe dehydration and fluid loss (Sathiadas, Mubarak, \& Arulmoli, 2016; Thapar \& Sanderson, 2004).

However, childhood diarrhoea is more deadly when it is associated with other health complications and illnesses. For example, when it is combined with pneumonia, the annual mortality rate was $40 \%$ higher than children who suffered with diarrhoea alone, and thus was termed as "The Fast Forgotten Killer of Children" worldwide (World Health Organization, 2009a). A related study revealed that malnourished children were also at high risk of dying 
when infected with diarrhoea because they could not resist the infectious agents due to their weak immune system (Breurec et al., 2016). In Solomon Islands, 1 in every 10 children was malnourished and more than 4,000 children were suffering from measles (Ministry of Health and Medical Sciences, 2016).

Globally, the high prevalence of diarrhoeal disease among the urban poor is rooted to the current growing inequality of income level between the developed and developing world. This had been statistically revealed in a study by Kakulu in 2012, which stipulated that more than $50 \%$ of childhood diarrhoea morbidity and mortality cases were reported from low income countries (Kakulu, 2012). Poverty was believed to be a root cause of poor child health all over the world, which had caused children to be socially, economically and environmentally vulnerable to dangers (Mohanty, 2006). It also reported that children residing in the poorest $20 \%$ of all households worldwide were far more likely to die before their fifth birthday than those living in the richest households. In fact, millions today are living in urban slums all over the world (Unicef, 2012). It was also reported that out of all the Millennium Development Goals (MDGs) targets, minimal support had been provided to improve the health of children U5y living in slums (Jones, 2012). This indicates an urgent need for the World Health Organisation (WHO) and the United Nation (UN) member countries like Solomon Islands, to recommit themselves to UN goals which are subjected to the health of children and mothers. Ongoing education and advocacy programmes among primary caregivers are of utmost necessity.

Socio-demographic factors often influence the daily activities of a human being of any household. They are age group, household size, education level, income level and others. In Solomon Islands context, the average household size that is economical and maintainable is five with a fortnightly income of above $\$ 1500$ (SBD) (Gagahe, 2011). This is considered the poverty level. Education is necessary because it has led to improved knowledge and recognition of signs and symptoms of diseases and guided appropriate care seeking behavior (Mukiira \& Ibisomi, 2012). Studies have revealed that economic status of a household is vital to assess because it indicates its financial capability to access essential services (Çera, Khan, Mlouk, \& Brabenec, 2020; Sherraden \& Ansong, 2016). In India, low socio-economic status has been shown to increase the burden of childhood diarrhoea (Banda et al., 2007).

Due to lack of previous studies conducted in Solomon Islands, this study aimed to determine factorsassociated with U5y old diarrhoeal disease among this specific vulnerable population within Mataniko informal settlements, in Solomon Islands.

\section{Methods}

This prospective cross sectional study was conducted at three out of six randomly selected Mataniko informal settlements, namely Mamana Wata, Lord Howe and Koa Hill (Figures 1 and 2) situated along the Mataniko River corridor, in Honiara, Solomon Islands from June to July 2016. The potential participants in any selected settlement were all households' (hlds) care-givers. However, only one care-giver was interviewed in each selected hld. In this study a 'caregiver' is refers to either a father or mother with at least a child (U5y). However, hlds without a child (U5y) were excluded in the study; and also hlds (U5y) who were unwilling to give their study consent and those having language barrier like mute person. In the analysis, those care-givers with more than one child (U5y) were treated the same as caregivers with only one child (U5y). Household interview was conducted after all successful participants were re-notified via community announcement. A call-back visit was made to re-visit care-givers who were absent in the first day.

A total of 205 caregivers were being interviewed using pre-tested survey questionnaire forms. Spatial data were geo-referenced using Global Positioning System (GPS) technology. The independent variables were socio-demographic (including age, sex, locality, number of under-five children, household size, education and income level) and the outcome variable was diarrhoea status of children U5y that was collected based on a 2-weeks recall. The raw data were then entered into SPSS version 23 . The data was then analyzed using descriptive statistics, followed by binary logistic regression to explore the relationship between the investigated variables. A $p$-value less than 0.05 was considered to be statistically significant. 


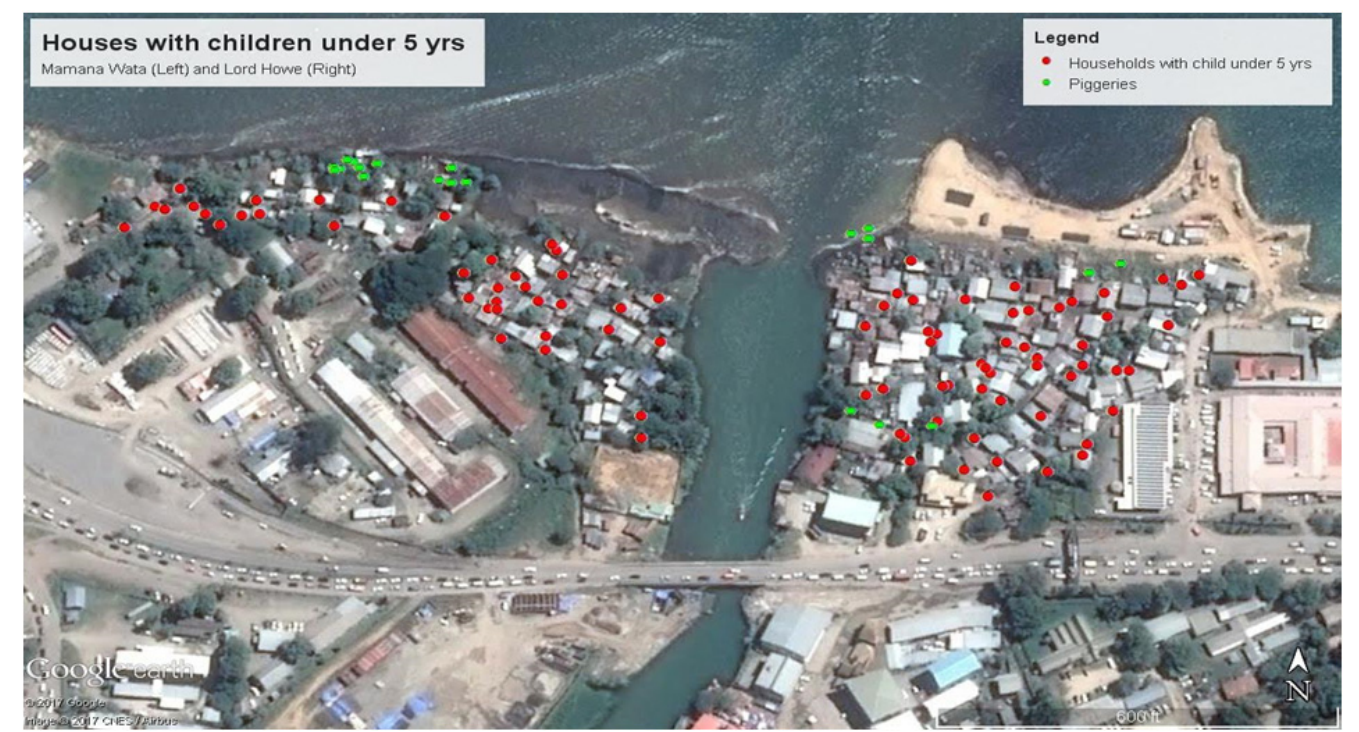

Figure 1. Map of Mamana Wata (left) and Lord Howe settlement (right) showing the U5y surveyed households

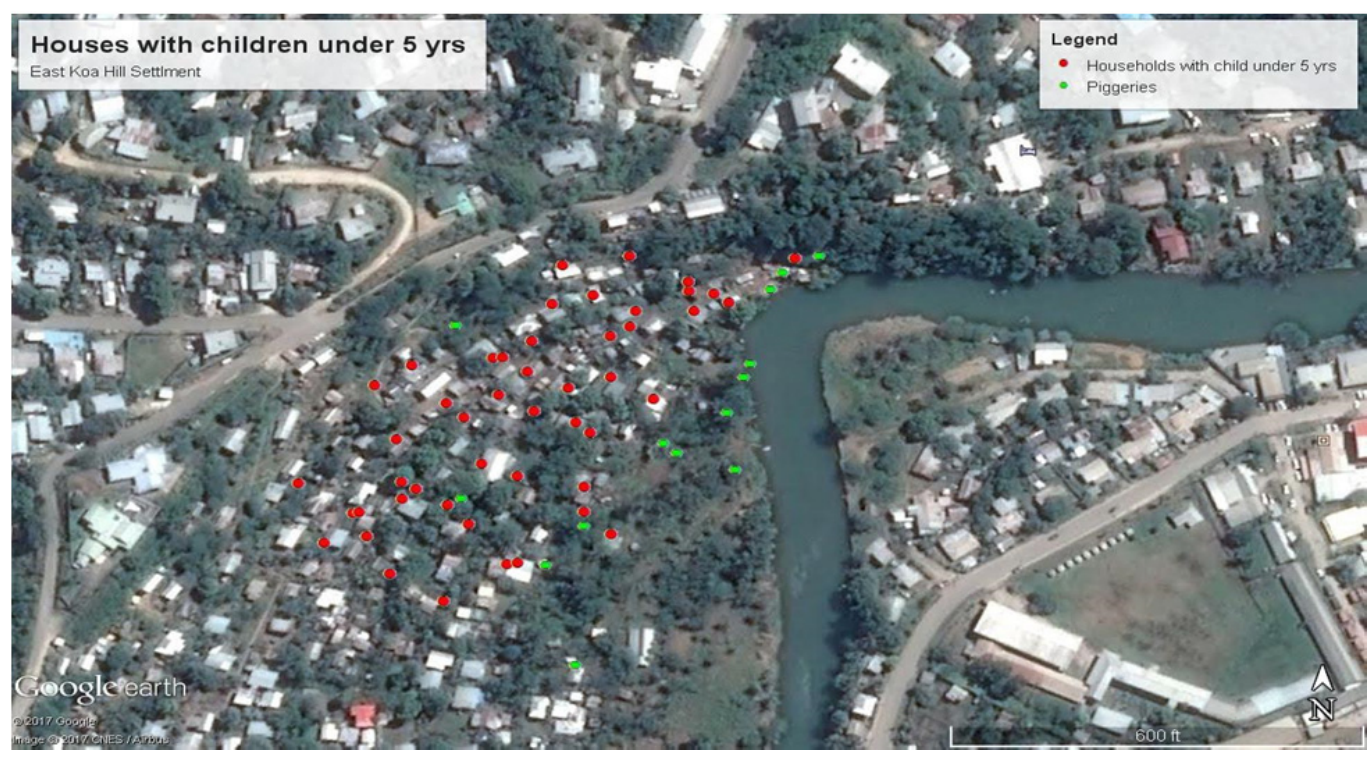

Figure 2. Map of East Koa Hill settlement showing the U5y surveyed households

\section{Results}

The mean ages of caregivers and U5y children were 30.7 ( $\pm 8.2 \mathrm{SD})$ years and $2.6( \pm 1.5 \mathrm{SD})$ years, respectively. This indicated a high concentration of younger caregivers as well as younger children ( $\leq 2$ yrs). The majority of caregivers were female $(95.0 \%)$ and were the mothers of the children. Nearly half $(41.0 \%)$ of the caregivers had 2 or more U5y children. In comparison to caregivers by locality, there was little discrepancy. However, participants from Koa Hill (38.0\%) had outnumbered Lord Howe (37.6\%) and Mamana Wata (24.4\%); and a majority (79\%) of them had resided for more than 5 years in their respective settlement. The average household size was $7.9( \pm$ 2.5SD); and most (79.5\%) of the caregivers resided in over-crowded conditions. In terms of formal education, $84.4 \%$ of caregivers had completed formal education and many were within low the education category (78.6\%). Furthermore, everyone had reported at least one source of income. Comparatively, many had depended on wages/salary (30.1\%) and market vendors (54.7\%) as major sources of household earning. In regards to fortnightly income level, only $9.8 \%$ accounted for high income level (Table 1). 
Table 1. Demographic characteristics of under-five children and caregivers

\begin{tabular}{|c|c|c|c|}
\hline Variables & Category & Frequency $(\mathrm{N}=205)$ & Percentage \\
\hline \multirow{2}{*}{ Age of child (in years) } & $\leq 2$ & 120 & 58.5 \\
\hline & $3-5$ & 85 & 41.5 \\
\hline \multirow{2}{*}{ Age of caregiver (in years) } & $\leq 29$ & 101 & 49.3 \\
\hline & $\geq 30$ & 104 & 50.7 \\
\hline \multirow{2}{*}{ Sex of caregiver } & Male & 10 & 5.0 \\
\hline & Female & 195 & 95.0 \\
\hline \multirow{3}{*}{ Locality (settlements) } & Mamana Wata & 50 & 24.4 \\
\hline & Lord Howe & 77 & 37.6 \\
\hline & Koa Hill & 78 & 38.0 \\
\hline \multirow{4}{*}{ No. of years lived in Mataniko IS } & $<12$ months & 12 & 6.0 \\
\hline & $1-2$ years & 16 & 8.0 \\
\hline & $3-5$ years & 16 & 8.0 \\
\hline & $>5$ years & 161 & 79.0 \\
\hline \multirow{2}{*}{ No. of U5y children per caregiver } & 1 child & 121 & 59.0 \\
\hline & $\geq 2$ children & 84 & 41.0 \\
\hline \multirow{2}{*}{ Household size } & Small & 42 & 20.5 \\
\hline & Big & 163 & 79.5 \\
\hline \multirow{3}{*}{ Formal education level } & No-education & 32 & 15.6 \\
\hline & Low & 136 & 66.3 \\
\hline & High & 37 & 18.0 \\
\hline \multirow{2}{*}{ Fortnightly income level } & Low & 182 & 88.8 \\
\hline & High & 23 & 11.2 \\
\hline
\end{tabular}

The results of this study showed that $45.9 \%$ of all caregivers had reported that their U5y children had suffered with at least one episode of diarrhoea within the last 2 weeks prior to the study. This prevalence rate $(45.9 \%)$ was exactly five times higher than the national U5y children diarrhoea prevalence rate (9.4\%) reported by the Solomon Islands National Statistics Office (SINSO) in 2007.

Table 2. Socio-demographic characteristics and under-five diarrhoea

\begin{tabular}{|c|c|c|c|c|c|}
\hline \multirow{2}{*}{ Variables } & \multirow{2}{*}{ Category } & \multicolumn{2}{|c|}{ Diarrhoeal Disease } & \multirow{2}{*}{$\begin{array}{l}\text { Bivariate } \\
\text { OR }(95 \% \mathrm{CI})\end{array}$} & \multirow{2}{*}{ p-value } \\
\hline & & Yes(\%) & No $(\%)$ & & \\
\hline \multirow{2}{*}{ Age of children } & $\leq 2$ years & $64(53.3)$ & $56(46.7)$ & $2.10(1.18,3.71)$ & \multirow{2}{*}{0.011} \\
\hline & $3-5$ years $^{+}$ & $30(35.3)$ & $55(64.7)$ & 1.0 & \\
\hline \multirow{2}{*}{ Age of caregivers } & $\leq 29$ years & $52(51.5)$ & $49(48.5)$ & $1.57(0.90,2.72)$ & \multirow{2}{*}{0.112} \\
\hline & $\geq 30$ years $^{+}$ & $42(40.4)$ & $62(59.6)$ & 1.0 & \\
\hline \multirow{2}{*}{ No. of U5y children per caregiver } & 1 child $^{+}$ & $47(38.8)$ & $74(61.2)$ & 1.0 & \multirow{2}{*}{0.016} \\
\hline & 2 children or more & $47(56.0)$ & $37(44.0)$ & $2.00(1.14,3.52)$ & \\
\hline \multirow{2}{*}{ Household size } & Small $^{+}$ & $14(33.3)$ & $28(66.7)$ & 1.0 & \multirow{2}{*}{0.071} \\
\hline & Large & $80(49.1)$ & $83(50.9)$ & $1.93(0.95,3.93)$ & \\
\hline \multirow{3}{*}{ Education level } & No-education & $12(37.5)$ & $20(62.5)$ & $0.71(0.27,1.85)$ & \multirow{3}{*}{0.479} \\
\hline & Low & $65(47.8)$ & $71(52.2)$ & $1.08(0.52,2.23)$ & \\
\hline & $\mathrm{High}^{+}$ & $17(45.9)$ & $20(54.1)$ & 1.0 & \\
\hline \multirow{2}{*}{ Income level } & Low income & $88(48.4)$ & $94(51.6)$ & $2.65(1.00,7.03)$ & \multirow{2}{*}{0.050} \\
\hline & High income $^{+}$ & $6(26.1)$ & $17(73.9)$ & 1.0 & \\
\hline
\end{tabular}

OR=Odd Ratio; $C I=$ Confident Interval; Statistically significant at $p<0.05$. 
As Table 2 shows, age of U5y children (in years), number of U5y children per caregiver, and fortnightly income level below $\$ 1500$ (SBD) were significantly associated with diarrhoea $(\mathrm{p}<0.05)$. On the other hand, U5y children diarrhoea was not significantly associated with age of caregivers (in years), household size, and education level.

Results further indicated that the odds of having diarrhoea were 2.1 times higher in younger children (aged $\leq 2$ years) compared to older children (aged 3-5 years) $(\mathrm{OR}=2.1,95 \% \mathrm{CI}: 1.18,3.71)$. Similarly, caregivers with two or more U5y children were two times more likely to report under-five diarrhoea infection than caregivers with only one child U5y ( $\mathrm{OR}=2.00,95 \% \mathrm{CI}: 1.14,3.52)$. Based on childcare experience, the chance of reporting U5y diarrhoeal cases increased by 1.57 times among younger caregivers (aged $\leq 29$ years) than older caregivers (aged $\geq 30$ years) ( $\mathrm{OR}=1.6,95 \% \mathrm{CI}: 0.90,2.72)$. Moreover, Table 2 showed that U5y children of caregivers living in large household size were 1.93 times (93\%) more likely to have diarrhoea (OR=1.93, 95\% CI: $0.95,3.93)$. As in other studies, results also demonstrated that children of caregivers from low income households were about 2.7 times more likely to have diarrhoea than children of caregivers from high income households (OR=2.65, $95 \% \mathrm{CI}$ : 1.00 , 7.03).

\section{Discussion}

In this study, the age group of U5y children was positively associated with diarrhoea morbidity. The odds of having diarrhoea was 2.1 times higher among younger children than older children. This is in agreement with a result of DHS in Solomon Islands (Solomon Islands National Statistics Office \& Inc, 2009), and studies conducted separately in Ethiopia by Mohammed \& Tamiru and Alambo, which revealed that diarrhoea was associated with U5y children in the age group 6-23 months and 12-23 months, respectively (Alambo, 2015; Mohammed \& Tamiru, 2014). This indicated that younger children ( $\leq 2$ years) should be given optimal parental care as one of the interventions to address this disease at the household level. Furthermore, within the younger age group or at least after six months, children started to receive a bit of solid food instead of milk and then often started moving around the house. In addition, crawling and other physical body changes like walking started within this age group (12-23 months) and the risk of picking up contaminated materials and putting them into their mouth is often high.

In comparison to age group of caregivers, this study failed to discover a direct association with under-five diarrhoea, though fewer cases (44.7\%) were identified among older caregivers; also the chance for their children to be infected with diarrhoea was decreased by $57 \%$ compared to younger caregivers. This contradicts a finding by Diouf and others in rural Burundi, in which they found that under-five diarrhoea was associated with mothers' age below 25 years (Diouf, Tabatabai, Rudolph, \& Marx, 2014). Nevertheless, both studies appreciated the fact that disease rates normally decreased among older caregivers because of increased childcare experience following older ages.

Concerning the number of U5y children per caregiver, it was found to have been significantly associated with under-five diarrhoea $(p<0.05)$. In addition, caregivers with two children or more were two times more likely to have reported under-five diarrhoea compared to caregivers with only one child. This coincides with a study conducted by Alambo in Wolitta Soddo Town, Southern Ethiopia (Alambo, 2015). This indicated that having many children ( $<5$ years) in a family had increased the chance of under-five diarrhoea and parental support in terms of food, water and time. It also demonstrated the urgent need for child birth spacing practice and education among childbearing couples in the study settlements.

Results further revealed that high cases $(85.1 \%)$ were reported by caregivers living in large household size, though such differences were not statistically significant ( $>0.05)$. The average household size was $7.9( \pm 2.5 \mathrm{SD})$ almost equal to an average household size of 8.4 found in Papua New Guinea (PNG) informal settlements (World Bank, 2014); but nearly doubled the national average household size of 5 people reported by the Solomon Islands National Statistics Office (Solomon Islands National Statistics Office \& Inc, 2009). This association is not in agreement with a community-based cross-sectional study conducted in 2014 in Nairobi, in Kenya (Muriithi, 2014). Nonetheless, since the chance of having diarrhoea were about twice as high among children living in large household sizes compared to those living in small household size, this indicated that overcrowded households can exert pressure on the available social amenities like water and toilet facilities, and as a result can contribute to childhood illnesses like diarrhoea. This also demonstrated that reduction of household size to 6 people or less is an important approach to reduce the occurrence of under-five diarrhoea. Another option would be creating more living rooms and effective family planning, a plan which is made in relation to parent's ability and affordability to basic household resources. As shown in the Solomon Islands Government (SIG) 2014 report, most living dwellings in Mataniko informal settlements were semi-permanent and non-permanent building structures, built without municipal approval and therefore, at high risk to medical related hazards (Government of Solomon Islands, 2014). 
Though education increases knowledge and caregiver care seeking behavior (Mukiira \& Ibisomi, 2012; Muriithi, 2014), this study was not able to determine a positive association between formal education level and under-five diarrhoea ( $>0.05)$, regardless of the fact that most $(69.1 \%)$ of the cases were reported by caregivers with low education level. This relationship is in agreement with a finding by Mukiira in 2012 (Mukiira \& Ibisomi, 2012), but is in contradiction with a finding by Muriithi David Ikua in 2014 (Muriithi, 2014); and also Mohammed \& Tamiru in Arba Minch District, Southern Ethiopia, which revealed that maternal education was significantly associated with under-five diarrhea. Mohammed \& Tamiru expanded that children whose mothers did not attend formal education were $89 \%$ more likely to develop diarrhoea, as compared to children whose mothers had attended formal education (Mohammed \& Tamiru, 2014). Despite such benefit, in the context of Mataniko informal settlements, education level cannot significantly reduce the prevalence of under-five diarrhoea, though hygiene practices of caregivers would be influenced by their level of education. This also means that there are other compounding factors that directly influence the spread of diarrhoeal-causing agents to children. For instance, most caregivers $(98.1 \%$ ) have knowledge of diarrhoea transmission and prevention, but due to the fact that the majority $(94.7 \%)$ of them have very low fortnightly income ( $\leq \$ 1500 \mathrm{SBD})$, they were unable to purchase safe drinking water from shops for their children in a daily basis, and to pay water bills to maintain regular access to water services at home. This explanation agrees with Matovu's finding in his study in Zimbabwe (Matovu, 2000). Further, there is a considerable difference between formal education attendees $(84.4 \%)$ and non-formal education attendees $(15.6 \%)$ in the study population, which may influence the analyzed result. Nevertheless, consistent health education for caregivers at the community level is a matter of concern, especially for those who did not attain formal education (15.6\%). As reported by Diouf et al, in rural Burundi informal settlements, lower prevalence of diarrhoea was discovered among children $(<5$ years $)$ whose primary caregivers had received hygiene education compared to their counterparts (Diouf, et al., 2014).

As in many studies, in this study, the household income level was also found to be one of the factors associated with under-five diarrhoea; and the odds of having diarrhoea were about 2.7 times higher among children whose caregivers had low fortnightly income. Furthermore, above ninety percent (94.7\%) of cases were reported by caregivers residing in low income households. This relationship is in line with Muriithi David Ikua and and Alambo's respective findings; and also Ahmed and Millard, which stated that household income level was associated with child's survival because it determines the financial capability of households to access basic life necessities like food and Water, Sanitation and Hygiene (WASH) services (Alambo, 2015; Muriithi, 2014). Previous studies also illustrated that the better the household income level, the less likely the child is to get a diarrhoeal disease (Opisa, Odiere, Jura, Karanja, \& Mwinzi, 2012; Uwizeye, Sokoni, \& Kabiru, 2014). As depicted in table 1, due to caregivers status of low income, most households were not in a position to buy optimum amounts of water to maintain proper hygiene practices and other essential household resources. In addition, in the context of Solomon Islands, the growth of urban informal settlements was not supported by the government in terms of urban social services provision (United Nations Human Settlements Programme, 2012). This was also discovered by Uwizeye and others within East African countries (Uwizeye, et al., 2014). Thus, this situation has required the intervention of the government and other responsible authorities. In particular, to engage informal dwellers with small income generating projects as to help them to improve their financial status suitable for urban life.

The impacts of socio-demographic characteristics, like crowded households with low income level in many households, in relation to the burden of under-five diarrhoea requires awareness and advocacy at the community level. Related programmes should be designed with the aim to influence positive behavioral change among mothers and their respective partners. As revealed in this study, having more than one U5y child in a family and low income level contributed to the increased prevalence of under-five diarrhoea. Undoubtedly, an adoption of appropriate family planning through child birth spacing, plus improved access to employment among families, can ease this burden in the study settlements. As alluded to by WHO, having a number of children that is easy to sustain in terms of food, shelter and other social services, including education and medication, is a wise decision which will result in a healthy family (World Health Organization, 2009b).

\subsection{Limitation of the Study}

However this study is the first study conducted among U5y children in Solomon Islands, and there are some limitations. The study was conducted in three informal settlements along the Mataniko River corridor, in Honiara, and therefore did not represent the entire population of U5y children in Honiara's informal settlements. The study directly involved primary caregivers instead of U5y children who were at a speaking age. This means that the number of times of passing watery stool per day, can be over reported by caregivers. In this situation there were no children (U5y) around to verify the responses concerning them. Moreover, some practices of children (U5y) including playing in the polluted river were not considered. 


\section{Conclusion}

A number of socio-demographic risk factors including, age group of U5y children, having at least 2 U5y children per caregiver and fortnightly income of $\$ 1,500$ (SBD) and below, were significantly associated with under-five diarrhoeal disease $(\mathrm{p}<0.05)$. To address these exposures, relevant programmes and projects should be designed, especially in areas like family planning, household economic empowerment and political commitment to a total WASH coverage initiative.

\section{Ethical Considerations}

Ethics approval was obtained from the Fiji National University (FNU), College Health Research and Ethics Committee (CHREC); and the Solomon Islands Ministry of Health, Research and Ethics Committee (SI-MoHREC) to conduct the study in Honiara, Solomon Islands.

\section{Acknowledgements}

We acknowledge our key informants and Research Assistants-Philemon Tohinoni and Dudley Kunu; and to the Solomon Islands Government (SIG) for funding this project. We also acknowledge Mr. Keshwa Krishna for his support.

\section{Funding}

This work was supported by grant from the SIG.

\section{Competing Interests Statement}

All authors declare that they have no conflict of interest.

\section{References}

Alambo, K. A. (2015). The prevalence of diarrheal disease in under five children and associated risk factors in Wolitta Soddo Town, Southern, Ethiopia. ABC Research Alert, 3(2), Ethiopia-Ethiopia.https://doi.org/10.18034/abcra.v3i2.295

Banda, K., Sarkar, R., Gopal, S., Govindarajan, J., Harijan, B. B., Jeyakumar, M. B., . . S Suresh, C. R. (2007). Water handling, sanitation and defecation practices in rural southern India: a knowledge, attitudes and practices study. Transactions of the royal society of tropical medicine and hygiene, 101(11), 1124-1130. https://doi.org/10.1016/j.trstmh.2007.05.004

Breurec, S., Vanel, N., Bata, P., Chartier, L., Farra, A., Favennec, L., . . Luong Nguyen, L. B. (2016). Etiology and epidemiology of diarrhea in hospitalized children from low income country: a matched case-control study in Central African Republic. PLoS neglected tropical diseases, 10(1), e0004283. https://doi.org/10.1371/journal.pntd.0004283

Çera, G., Khan, K. A., Mlouk, A., \& Brabenec, T. (2020). Improving financial capability: the mediating role of financial behaviour. Economic Research-Ekonomska Istraživanja, $1-18$. https://doi.org/10.1080/1331677X.2020.1820362

Chongsuvivatwong, V., Phua, K. H., Yap, M. T., Pocock, N. S., Hashim, J. H., Chhem, R., . . Lopez, A. D. (2011). Health and health-care systems in southeast Asia: diversity and transitions. The Lancet, 377(9763), 429-437. https://doi.org/10.1016/S0140-6736(10)61507-3

Diouf, K., Tabatabai, P., Rudolph, J., \& Marx, M. (2014). Diarrhoea prevalence in children under five years of age in rural Burundi: an assessment of social and behavioural factors at the household level. Global health action, 7(1), 24895. https://doi.org/10.3402/gha.v7.24895

Gagahe, N. (2011). Report on 2009 population and housing census. Solomon Islands population and housing census. National Statistic Office, Honiara, 17.

Government of Solomon Islands. (2014). Rapid Assessment of the Macro and Sectoral Impacts of Flash Floods in the Solomon Islands, April 2014.

Jones, P. (2012). The challenges of implementing Millennium Development Goal target 7D in Pacific island towns and cities. Asia-Pacific Development Journal, 19(1), 139-162. https://doi.org/10.18356/eb276182-en

Kakulu, R. K. (2012). Diarrhoea among under-five children and household water treatment and safe storage factors in Mkuranga district, Tanzania. Muhimbili University of Health and Allied Sciences.

Matovu, G. (2000). Upgrading Urban Low-Income Settlements in Africa: Constraints, Potentials, and Policy Options. Regional Roundtable on Upgrading Low-Income Settlements, 3-5. 
Ministry of Health and Medical Sciences. (2016). Solomon Islands National Health Strategic Plan (SINHSP) 2016-2020. Solomon Islands Government, Honiara. 2016.

Mohammed, S., \& Tamiru, D. (2014). The burden of diarrheal diseases among children under five years of age in Arba Minch District, southern Ethiopia, and associated risk factors: a cross-sectional study. International scholarly research notices, 2014. https://doi.org/10.1155/2014/654901

Mohanty, M. (2006). Squatters, vulnerability and adaptability of urban poor in a small island developing state: the context of Fiji Islands.

Mukiira, C. K., \& Ibisomi, L. (2012). Healthcare-seeking practices of caregivers of under-five children with diarrheal diseases in two informal settlements in Nairobi, Kenya. University of the Witwatersrand, Faculty of Humanities (Demography and ....

Muriithi, D. I. (2014). Risk factors influencing diarrhoea occurrence among children under five years old in informal urban settlements: A case study of Korogocho, in Nairobi county, Kenya. University of Nairobi.

Opisa, S., Odiere, M. R., Jura, W. G., Karanja, D. M., \& Mwinzi, P. N. (2012). Faecal contamination of public water sources in informal settlements of Kisumu City, western Kenya. Water Science and Technology, 66(12), 2674-2681. https://doi.org/10.2166/wst.2012.503

Sathiadas, M., Mubarak, F., \& Arulmoli, S. (2016). Clinical manifestations and microbiology of Shigella diarrhoea in children admitted to Teaching Hospital, Jaffna, Sri Lanka. Sri Lankan Journal of Infectious Diseases, 6(2). https://doi.org/10.4038/sljid.v6i2.8110

Sherraden, M. S., \& Ansong, D. (2016). Financial literacy to financial capability: Building financial stability and security International handbook of financial literacy (pp. 83-96). Springer. https://doi.org/10.1007/978-981-10-0360-8_7

Solomon Islands National Statistics Office, S. o. t. P. C., \& Inc, M. I. (2009). Solomon Islands Demographic and Health Survey 2006-2007.

Stella, M. Y., Huang, Z. J., \& Singh, G. K. (2004). Health status and health services utilization among US Chinese, Asian Indian, Filipino, and other Asian/Pacific Islander children. Pediatrics, 113(1), 101-107. https://doi.org/10.1542/peds.113.1.101

Thapar, N., \& Sanderson, I. R. (2004). Diarrhoea in children: an interface between developing and developed countries. The Lancet, 363(9409), 641-653. https://doi.org/10.1016/S0140-6736(04)15599-2

Unicef. (2004). Joint statement: clinical management of acute diarrhoea. Geneva: World Health Organization.

Unicef. (2012). The state of the world's children 2012: children in an urban world: eSocialSciences.

United Nations Human Settlements Programme. (2012). Solomon Islands: Honiara Urban Profile: United Nations Human Settlements Programme.

Uwizeye, D., Sokoni, C. H., \& Kabiru, C. W. (2014). Prevalence and correlates for diarrhoea in the mountainous informal settlements of Huye town, Rwanda. SpringerPlus, 3(1), 745. https://doi.org/10.1186/2193-1801-3-745

Wardlaw, T., Salama, P., Brocklehurst, C., Chopra, M., \& Mason, E. (2010). Diarrhoea: why children are still dying and what can be done. The lancet, 375(9718), 870-872. https://doi.org/10.1016/S0140-6736(09)61798-0

World Bank. (2014). Papua New Guinea - Sanitation, Water Supply and Hygiene in Urban Informal Settlements. Water and Sanitation Program, World Bank Group, Washington DC.

World Health Organization. (2009a). Diarrhoea: why children are still dying and what can be done.

World Health Organization. (2009b). Milestones in health promotion: Statements from global conferences: World Health Organization.

World Health Organization. (2015). Solomon Islands health system review: Manila: WHO Regional Office for the Western Pacific.

\section{Copyrights}

Copyright for this article is retained by the author(s), with first publication rights granted to the journal.

This is an open-access article distributed under the terms and conditions of the Creative Commons Attribution license (http://creativecommons.org/licenses/by/4.0/). 
Predictors of under Five Years Old

Diarrhoeal Disease in Mataniko Informal Settlements in Solomon Islands

\author{
Gali, A
}

2021 